\title{
HUBUNGAN PENGETAHUAN, JUMLAH ANAK DAN UMUR DENGAN PENGGUNAAN KONTRASEPSI SUNTIK
}

\author{
Susmini $^{1}$, Ismiati $^{2}$ \\ ${ }^{1}$ Politeknik Kesehatan Kemenkes Palembang, Prodi Keperawatan Lubuklinggau \\ Jalan Stadion Silampari Kota Lubuklinggau \\ ${ }^{2}$ Politeknik Kesehatan Kementerian Kesehatan Bengkulu, Jurusan Kebidanan, \\ Jalan Indragiri Nomor 03 Padang Harapan Kota Bengkulu \\ jmkbengkulu@gmail.com
}

\begin{abstract}
KB formulated as an effort to increase awareness and public participation under the age limit of marriage, birth control, fostering family resilience, improving the welfare of the family to realize a small family happy and prosperous (BKKBN, 2011). The purpose of this study to determine the relationship of Knowledge, Number of Children (Parity) and Age With Injectable Contraceptive Use In Puskesmas Megang District of North Lubuklinggau II Lubuklinggau 2014. This study used a survey method with cross sectional Analytical. With a total population of 325 people. Sampling by means of random sampling. The respondents are all over acceptors in Puskesmas Megang District of North Lubuklinggau II Lubuklinggau 2014 totaling 65 people. From the research of 65 respondents obtained knowledge with the use of injectable contraceptives, respondents Knowledge obtained the highest results were knowledgeable enough respondents was 25 (38.5\%) of respondents. From the research of 65 respondents Number of respondents children obtained the highest results that respondents with the number of children a little $\leq 2$ there were $33(50.8 \%)$ of respondents who use injectable contraceptives. From the research of 65 respondents to the Age of respondents obtained the highest results were age with low risk (age 20-35 years) amounted to 49 (75.4\%) of respondents who use injectable contraceptives. From the results of bivariate analysis showed no significant relationship between knowledge and injectable contraceptives $p$ value $=0.131$, the results of the bivariate also showed no significant relationship between the number of children with CICs $p$ value $=0.329$ and the results of the bivariate also showed a significant relationship between age CICs with $p$ value $=0,040$. Results of this research are expected to be a driving force for health workers, especially Puskesmas Megang District of North Lubuklinggau II Lubuklinggau to provide education on contraception mamfaat to adjust the spacing births.
\end{abstract}

Keywords: Knowledge, Children, Age, Contraception

\begin{abstract}
Abstrak : KB dirumuskan sebagai upaya peningkatan kepedulian dan peran serta masyarakat melalui batas usia perkawinan, pengaturan kelahiran, pembinaan ketahanan keluarga, peningkatan kesejahteraan keluarga untuk mewujudkan keluarga kecil bahagia dan sejahtera (BKKBN, 2011). Tujuan penelitian ini untuk mengetahui Hubungan Pengetahuan, Jumlah Anak (Paritas) dan Umur Dengan Penggunaan Kontrasepsi Suntik Di Puskesmas Megang Kecamatan Lubuklinggau Utara II Kota Lubuklinggau Tahun 2014. Penelitian ini menggunakan metode Survey Analitik dengan pendekatan Cross Sectional. Dengan jumlah populasi sebanyak 325 orang. Pengambilan sampel dengan cara Random Sampling. Adapun responden adalah seluruh akseptor KB di Puskesmas Megang Kecamatan Lubuklinggau Utara II Kota Lubuklinggau Tahun 2014 yang berjumlah 65 orang. Dari hasil penelitian dari 65 responden didapatkan pengetahuan dengan penggunaan kontrasepsi suntik, Pengetahuan responden diperoleh hasil tertinggi yaitu responden yang berpengetahuan cukup berjumlah $25(38,5 \%)$ responden. Dari hasil penelitian dari 65 responden Jumlah anak responden diperoleh hasil tertinggi yaitu responden dengan jumlah anak sedikit $\leq 2$ orang ada $33(50,8 \%)$ responden yang menggunakan kontrasepsi suntik. Dari hasil penelitian dari 65 responden dengan Umur responden diperoleh hasil tertinggi yaitu umur dengan resiko rendah (umur 20-35 tahun) berjumlah $49(75,4 \%)$ responden yang menggunakan kontrasepsi suntik. Dari hasil analisa bivariat menunjukan tidak ada hubungan yang bermakna antara pengetahuan dengan kontrasepsi suntik $\mathrm{p}$ value $=0,131$, hasil bivariat juga menunjukan tidak ada hubungan yang bermakna antara jumlah anak dengan kontrasepsi suntik $p$
\end{abstract}


value $=0,329$ dan hasil bivariat juga menunjukan ada hubungan yang bermakna antara umur dengan kontrasepsi suntik $\mathrm{p}$ value $=0,040$. Hasil penelitian ini diharapkan menjadi pendorong bagi petugas kesehatan khususnya Puskesmas Megang Kecamatan Lubuklinggau Utara II Kota Lubuklinggau untuk memberikan penyuluhan tentang mamfaat kontrasepsi untuk mengatur jarak kelahiran.

\section{Kata Kunci $\quad$ : Pengetahuan, Anak, Umur, Kontrasepsi}

Pemerintah Indonesia telah merancangkan berbagai program untuk menangani masalah kependudukan yang ada. Salah satu programnya dengan Keluarga Berencana Nasional sebagai integral dari pembangunan nasional yang mempunyai tujuan ganda yaitu mewujudkan pembangunan yang berwawasan kependudukan dan mewujudkan keluarga kecil bahagia sejahtera. Keadaan ini dapat dicapai dengan menganjurkan PUS (Pasangan usia subur) untuk mengikuti Program Keluarga Berencana (BKKBN, 2011). Keluarga berencana adalah usaha untuk mengukur jumlah dan jarak anak yang diinginkan. Agar dapat mencapai hal tersebut, maka dibuatlah beberapa cara atau alternatif untuk mencegah atau menunda kehamilan.Cara tersebut termasuk kontrasepsi atau pencegahan kehamilan dan perencanaan keuarga. Tujuan umum program KB adalah membentuk keluarga kecil sesuai dengan ke-kuatan sosial ekonomi suatu keluarga dengan cara pengaturan kelahiran anak, agar diperoleh suatu keluarga bahagia dan sejahtera yang dapat memenuhi kebutuhan hidupnya. Tujuan lain meliputi pengaturan kelahiran, pendewasaan usia perkawinan, peningkatan ketahanan dan kesejahteraan keluarga (BKKBN, 2011).

Visi program keluarga berencana adalah pelayanan KB dan kesehatanreproduksi yang berkualitas telah menjadi tuntunan masyarakat, disamping merupakan kewajiban pemerintah dan memberikan pelayanan untuk menyediakannya. Oleh karena itu pelayanan keluarga berencana dan kesehatan reproduksi tidak lagi berorientasi pada pencapaian kualitas tetapi berorientasi pada pemenuhan, permintaan, serta menyediakan pelayanan yang berkualitas (BKKBN, 2011).

Indonesia merupakan negara yang dilihat dari jumlah penduduknya ada pada posisi keempat di dunia, dengan laju pertumbuhan yang masih relatif tinggi. Esensi tugas program Keluarga Berencana (KB) dalam hal ini telah jelas yaitu menurunkan fertilitas agar dapat mengurangi beban pembangunan demi terwujudnya kebahagiaan dan kesejahteraan bagi rakyat dan bangsa Indonesia. Tetapi pertumbuhan di Indonesia terus meningkat setiap tahunnya. Hasil proyeksi Badan Pusat Statistik (BPS) menunjukan jumlah penduduk Indonesia tahun 2010 mencapai 231,4 juta dan menjadi 249,7 juta pada tahun 2015. Jika laju penduduk di indonesia saat ini stagnan pada 1,3\%, maka diperkirakan jumlah penduduk indonesia akan meningkat dua kali lipat setiap 50 tahun. Kenaikan jumlah penduduk berdampak pada persoalan ketahan pangan, pemenuhan kebutuhan energi, pengendalian lingkungan hidup, dan rendahnya indeks pembangunan manusia (IPM) Indonesia. Saat ini Indonesia berada pada peringkat 108 dari 162 negara (PKBI, 2010)

Ada beberapa metode KB yang dapat digunakan meliputi metode sederhana (kondom, spermisida, koitus interuptus, pantang berkala), metode efektif dengan hormonal (pil KB, suntikan $\mathrm{KB}$, susuk KB, IUD/AKDR), dan metode mantap dengan cara operasi yaitu tubektomi dan vasektomi (Manuaba,2010).

Ada beberapa faktor yang memengaruhi keikutsertaan wanita PUS dalam penggunaan $\mathrm{KB}$ antara lain faktor pengetahuan, umur, ekonomi, jumlah anak, partisipasi suami, dan pelayanan KB (Hartanto, 2009) dan menurut BKKBN (2009) faktor yang mempengaruhi penggunaan $\mathrm{KB}$ yaitu faktor individu (umur, lama menikah, pekerjaan,pendidikan, jumlah anak), faktor program ( pengetahuan tentang $\mathrm{KB}$, informed choiced, dan informed consent), faktor lingkungan (peran pasangan, media informasi, peran petugas), faktor sarana (ketersediaan alat kontrasepsi, tempat pelayanan, dan biaya).

Banyak wanita harus menentukan pilihan kontrasepsi yang sulit. Tidak hanya terbatasnya jumlah metode yang tersedia, tetapi juga karena metode-metode tersebut mungkin tidak dapat 
diterima sehubungan dengan kebijakan nasional $\mathrm{KB}$, kesehatan individu, dan seksualitas wanita atau biaya untuk memperoleh kontrasepsi. Dalam memilih suatu metode, wanita harus mempertimbangkan berbagai faktor, termasuk status kesehatan mereka, efek samping potensial suatu metode, konsekuensi terhadap kehamilan yang tidak diinginkan, kerjasama pasangan, dan norma budaya mengenai kemampuan mempunyai anak ( Maryani,2008).

Setiap metode mempunyai kelebihan dan kekurangan. Namun demikian, meskipun telah mempertimbangkan untung rugi semua kontrasepsi yang tersedia tetap saja terdapat kesulitan untuk mengontrol fertilitas secara aman, efektif, dengan metode yang dapat diterima, baik secara perseorangan maupun budaya pada berbagai tingkat reproduksi. Tidaklah mengejutkan apabila banyak wanita merasa bahwa penggunaan kontrasepsi terkadang problematik dan mungkin terpaksa memilih metode yang tidak cocok dengan konsekuensi yang merugikan atau tidak menggunakan metode KB sama sakali (Hartanto, 2009). Penelitian ini bertujuan untukmengetahui hubungan pengetahuan, jumlah anak (paritas) dan umur dengan penggunaan kontrasepsi suntik Di Puskesmas Megang Kecamatan Lubuklinggau Utara II Kota Lubuklinggau Tahun 2014

\section{BAHAN DAN CARA KERJA}

Jenis penelitian yang digunakan metode deskriptif analitik dengan pendekatan Cross Sectional. Sampel dalam penelitian ini adalah 65 orang. Pengambilan sampel dengan cara random sampling. Jika besar populasi $\leq 1000$ maka besar sampel bisa diambil 10-30\%. Populasi pada penelitian ini adalah 325 orang. Penelitian menggunakan nilai persentase $20 \%$.

Analisa bivariat menggunakan uji statistik Chi Square dengan tingkat kepercayaan $=0,05$.

\section{HASIL}

Dari tabel 1 diatas menunjukan bahwa responden yang mempunyai pengetahuan baik ada $16(24,6 \%)$ responden, berpengetahuan cukup ada $25(38,5 \%)$ responden, dan yang berpengetahuan kurang ada $24(36,9 \%)$ responden. Dari tabel diatas menunjukan bahwa $33(50,8 \%)$ responden mempunyai anak sedikit ( $\leq 2$ orang) dan $32(49,2 \%)$ responden mempunyai anak banyak ( $>2$ orang). Dari tabel diatas menunjukan bahwa $49(75,4 \%)$ respoden mempunyai resiko rendah umur 20-35 tahun dan $16(24,6 \%)$ responden yang mempunyai resiko tinggi umur $<20$ tahun dan > 35 tahun. Dari tabel diatas menunjukan bahwa responden yang menggunakan kontrasepsi suntik sebanyak $44(67,7 \%)$ responden dan responden yang tidak menggunakan kontrasepsi suntik sebanyak $21(32,3 \%)$ responden.

Tabel 1 Distribusi Frekuensi Karakterisktik Responden

\begin{tabular}{lcc}
\hline Variabel & Frekuensi & Presentase (\%) \\
\hline Pengetahuan & & \\
Baik & 16 & 24,6 \\
Cukup & 25 & 38,5 \\
Kurang & 24 & 36,9 \\
Jumlah Anak & & \\
$\begin{array}{l}\text { Sedikit } \leq 2 \text { orang } \\
\text { Banyak > } 2 \text { orang }\end{array}$ & 33 & 50,8 \\
Umur rendah & 32 & 49,2 \\
$\begin{array}{l}\text { Resiko } \\
\text { umur 20-35 tahun }\end{array}$ & 49 & 75,4 \\
$\begin{array}{l}\text { Resiko tinggi umur } \\
<\text { 20 tahun dan >35 }\end{array}$ & 16 & 24,6 \\
tahun \\
$\begin{array}{l}\text { Penggunaan } \\
\text { kontrasepsi } \\
\text { kontrasepsi suntik } \\
\text { bukan kontrasepsi }\end{array}$ \\
suntik
\end{tabular}

Tabel 2 Hubungan Pengetahuan, Jumlah Anak dan Umur dengan Penggunaan Kontrasepsi Suntik

\begin{tabular}{|c|c|c|c|c|c|c|c|}
\hline \multirow{3}{*}{ Variabel } & \multicolumn{4}{|c|}{$\begin{array}{c}\text { Penggunaan } \\
\text { kontrasepsi suntik }\end{array}$} & \multirow{2}{*}{\multicolumn{2}{|c|}{ Total }} & \multirow{3}{*}{$p$} \\
\hline & \multicolumn{2}{|c|}{ Suntik } & \multicolumn{2}{|c|}{$\begin{array}{l}\text { Bukan } \\
\text { suntik }\end{array}$} & & & \\
\hline & $\mathrm{n}$ & $\%$ & $\mathrm{n}$ & $\%$ & $\mathrm{n}$ & $\%$ & \\
\hline \multicolumn{8}{|l|}{ Pengetahuan } \\
\hline Baik- cukup & 31 & 75,6 & 10 & 24,4 & 41 & 100 & \multirow{2}{*}{0,131} \\
\hline Kurang & 13 & 54,2 & 11 & 40,0 & 24 & 100 & \\
\hline \multicolumn{8}{|l|}{ Jumlah anak } \\
\hline $\begin{array}{l}\text { Sedikit } \leq 2 \\
\text { orang }\end{array}$ & 20 & 60,6 & 13 & 39,4 & 33 & 100 & \multirow{2}{*}{0,329} \\
\hline $\begin{array}{l}\text { Banyak }>2 \\
\text { orang }\end{array}$ & 24 & 75,0 & 8 & 25,0 & 32 & 100 & \\
\hline \multicolumn{8}{|l|}{ Umur } \\
\hline $\begin{array}{l}\text { Resiko rendah } \\
\text { umur 20-35 } \\
\text { tahun }\end{array}$ & 37 & 75,5 & 12 & 24,5 & 49 & 100 & \\
\hline $\begin{array}{l}\text { Resiko tinggi } \\
\text { umur }<20 \\
\text { tahun dan }>35 \\
\text { tahun }\end{array}$ & 7 & 43,8 & 9 & 56,3 & 16 & 100 & 0,040 \\
\hline
\end{tabular}

Dari tabel 2 diatas hasil analisis hubungan antara pengetahuan dengan penggunaan kontrasepsi suntik, pengetahuan responden dengan kategori cukup-baik ada $31(75,6 \%)$ yang 
menggunakan kontrasepsi suntik, sedangkan pada responden dengan pengetahuan kurang ada 13 (54,2\%) yang menggunakan kontrasepsi suntik. Hasil uji statistis dengan Chi Square diperoleh $p=0,131>\alpha=0,05$. Sehingga disimpulkan bahwa tidak ada hubungan antara pengetahuan dengan penggunaan kontrasepsi suntik.

Tabel 2 diatas hasil analisis hubungan antara jumlah anak dengan penggunaan kontrasepsi suntik diperoleh responden dengan anak sedikit $\leq 2$ orang ada $20(60,6 \%)$ yang menggunakan kontrasepsi suntik, sedangkan pada responden dengan jumlah anak banyak $>2$ orang ada $24(75,0 \%)$ yang meggunakan kontrasepsi suntik . Hasil uji statistis dengan Chi Square diperoleh $p$ value $=0,329>\alpha=0,05$. Sehingga disimpulkan bahwa tidak ada hubungan antara jumlah anak dengan penggunaan kontrasepsi suntik.

Tabel 2 diatas hasil analisis hubungan antara Umur dengan penggunaan kontrasepsi suntik diperoleh responden dengan umur resiko rendah ada $37(75,5 \%)$ yang menggunakan kontrasepsi suntik, sedangkan responden dengan umur resiko tinggi ada 7 (43,8\%) yang menggunakan kontrasepsi suntik. Hasil uji statistis dengan Chi Square diperoleh $p$ value $=0,040>$ $\alpha=0,05$. Sehingga disimpulkan bahwa ada hubungan antara umur dengan penggunaan kontrasepsi suntik.

\section{PEMBAHASAN}

\section{Hubungan Pengetahuan Dengan Penggunaan Kontrasepsi Suntik.}

Dari hasil penelitian 65 responden didapatkan responden yang mempunyai pengetahuan baik ada $16(24,6 \%)$ responden, berpengetahuan cukup ada $25(38,5 \%)$ responden, dan yang berpengetahuan kurang ada 24 (36,9\%) responden. Penelitian Kusniah (2004) di Yogyakarta dengan pengetahuan tentang KB suntik baik sebanyak $75 \%$, Responden dengan pengetahuan tentang $\mathrm{KB}$ suntik cukup sebanyak $52,6 \%$ dan Responden yang memiliki pengetahuan tentang $\mathrm{KB}$ suntik kurang sebanyak $57,1 \%$.

Hasil analisa hubungan antara pengetahuan dengan penggunaan kontrasepsi suntik, pengetahuan responden dengan kategori cukup- baik ada $31(75,6 \%)$ yang menggunakan kontrasepsi suntik, sedangkan pada responden dengan pengetahuan kurang ada $13(54,2 \%)$ yang menggunakan kontrasepsi suntik. Hasil uji statistis dengan Chi Square diperoleh $p$ value $=$ $0,131>\alpha=0,05$. Sehingga disimpulkan bahwa tidak ada hubungan antara pengetahuan dengan penggunaan kontrasepsi suntik. Hasil penelitian ini sama dengan yang dilakukan oleh Kusniah (2004) dengan didapat nilai diperoleh $p$ value $=$ $0,059>\alpha=0,05$. Sehingga disimpulkan bahwa tidak ada hubungan antara pengetahuan dengan penggunaan kontrasepsi.

Pengetahuan adalah merupakan hasil "tahu", dan ini terjadi setelah orang melakukan pengidaraan terhadap satu obyek tertentu (Notoatmodjo, 2003). Hal ini tidak sesuai dengan pendapat Notoatmodjo (2003) yang mengatakan bahwa Pengetahuan merupakan faktor yang sangat penting dalam membentuk tindakan seseorang, karena perilaku yang didasari oleh pegetahuan akan lebih lama daripada perilaku yang tidak didasari oleh pengetahuan.

Menurut teori Green, dalam notoatmodjo (2005) perilaku kesehatan dalam menggunakan kontrsepsi tidak hanya di pengaruhi oleh predisposing factor yaitu pengetahuan melainkan dapat juga dipengaruhi oleh enabling factor atau factor yang memungkinkan seperti ketersediaan sarana dan prasarana atau fasilitas kesehatan bagi masyarakat, seperti : fasilitas dan petugas kesehatan. Untuk berprilaku sehat masyarakat memerlukan sarana dan prasarana pendukung. Dan dipengaruhi oleh reinforcing factor atau factor pendorong seperti tokoh masyarakat, tokoh agama, keluarga, suami dan teman.

Menurut pendapat peneliti kontrasepsi tidak hanya dipengaruhi oleh pengetahuan saja, tetapi juga banyak wanita harus menentukan pilihan kontrasepsi yang sulit tidak hanya karena terbatasnya jumlah metode yang tersedia tetapi dalam hal ini banyak wanita memilih suatu metode, wanita harus menimbang berbagai faktor termasuk status kesehatan mereka, efek samping potensial suatu metode, konsekuensi terhadap kehamilan yang tidak diinginkan, besarnya keluarga yang diinginkan, kerjasama pasangan, dan norma budaya mengenai kemampuan mempunyai anak. 


\section{Hubungan Jumlah Anak Dengan Penggunaan Kontrasepsi Suntik.}

Dari hasil penelitian 65 responden didapatkan bahwa $33(50,8 \%)$ responden mempunyai anak sedikit ( $\leq 2$ orang) dan $32(49,2$ $\%)$ responden mempunyai anak banyak (> 2 orang). Dari hasil penelitian Siregar (2010) sebanyak 27 responden $(77,1 \%)$ mempunyai anak sedikit ( $\leq 2$ orang) dan 18 responden $(22,9 \%)$ mempunyai anak banyak (> 2 orang).

Hasil dari analisa hubungan jumlah anak dengan penggunaan kontrasepsi suntik responden dengan anak sedikit $\leq 2$ orang ada 20 $(60,6 \%)$ yang menggunakan kontrasepsi suntik, sedangkan pada responden dengan jumlah anak banyak $>2$ orang ada $24(75,0 \%)$ yang meggunakan kontrasepsi suntik . Hasil uji statistis dengan Chi Square diperoleh $p$ value $=$ $0,329>\alpha=0,05$. Sehingga disimpulkan bahwa tidak ada hubungan antara jumlah anak dengan penggunaan kontrasepsi suntik. Hasil penelitian ini sama dengan penelitian Siregar (2010) dengan nilai $p$ value $=0,288$ sehingga didapat tidak ada hubungan antara jumlah anak dengan penggunan kontrasepsi suntik.

Anak adalah harapan atau cita-cita dari sebuah perkawinan. Berapa jumlah yang diinginkan, tergantung dari keluarga itu sendiri. Apakah satu, dua, tiga dan seterusnya. Dengan demikian keputusan untuk memiliki sejumlah anak adalah sebuh pilihan yang mana pilihan tersebut sangat dipengaruhi oleh nilai yang dianggap sebagai satu harapan atas setiap keinginan yang dipilih oleh orang tua. Program $\mathrm{KB}$ selain upaya untuk mewujudkan keluarga berkualitas melalui promosi, perlindungan dan bantuan dalam mewujudkan hak-hak reproduksi juga untuk penyelenggaraan pelayanan, pengaturan dan dukungan yang diperlukan untuk membentuk keluarga dengan usis kawin yang ideal,mengatur jumlah, jarak dan usia ideal melahirkan anak (Notoatmodjo, 2005).

Hal ini tidak sesuai dengan pendapat Mantra (2006) mengatakan bahwa kemungkinan seorang istri untuk menambah kelahiran tergantung kepada jumlah anak yang telah dilahirkannya. Seorang istri mungkin menggunakan alat kontrasepsi setelah mempunyai jumlah anak tertentu dan juga umur anak yang masih hidup. Semakin sering seorang wanita melahirkan anak, maka akan semakin memiliki risiko kematian dalam persalinan.

Menurut teori Redita (2010) mengatakan penggunaan kontrasepsi suntik tidak hanya dipengaruhi oleh umur dan jumlah anak saja tetapi masih banyak factor lain yang dapat mempengaruhi dalam penggunaan kontrasepsi antara lain pendidikan, sikap, pengetahuan, perilaku, dukungan, suami, tingkat ekonomi, dan agama. Selain itu kita harus mengetahui juga jenis kontrasepsi yang dipakai apakah kontrasepsi jangka panjang seperti Tubectomy atau Vasektomy atau kontrasepsi jangka pendek seperti pil,kondom, IUD, implant dan khususnya suntik.

Menurut pengamatan dan pendapat peneliti bahwa sekarang ini banyak wanita memilih kontrasepsi yang lebih simpel dan murah mungkin karena diakibatkan oleh keadaan ekonomi masing-masing, padahal pemakaian kontrasepsi dengan biaya yang murah tingkat keamanan untuk tidak hamil lagi semakin kecil. Selain itu kebutuhan ekonomi juga semakin besar semakin banyak anak semakin banyak juga biaya yang akan dikeluarkan.

\section{Hubungan Umur Dengan Penggunaan Kontrasepsi Suntik}

Dari hasil penelitian 65 responden didapatkan bahwa $49(75,4 \%)$ respoden mempunyai resiko rendah umur 20-35 tahun dan $16(24,6 \%)$ responden yang mempunyai resiko tinggi umur $<20$ tahun dan > 35 tahun. Hasil penelitian yang dilakukan Etty (2010) di Di Rsu Sari Mutiara Medan didapatkan bahwa umur 26-30 tahun (78\%) dan yang berumur $>30$ tahun $(22 \%)$.

Hasil analisa hubungan antara umur dengan penggunaan kontrasepsi suntik responden dengan umur resiko rendah ada 37 (75,5\%) yang menggunakan kontrasepsi suntik, sedangkan responden dengan umur resiko tinggi ada $7(43,8 \%)$ yang menggunakan kontrasepsi suntik. Hasil uji statistis dengan Chi Square diperoleh $p$ value $=0,040<\alpha=0,05$. Sehingga disimpulkan bahwa ada hubungan antara umur dengan penggunaan kontrasepsi suntik.

Hasil penelitian ini sama dengan Hasil penelitian yang dilakukan Etty (2010) di Di Rsu Sari Mutiara Medan didapatkan nilai $p$ value $=$ 0,036 Sehingga disimpulkan bahwa ada 
hubungan antara umur dengan penggunaan kontrasepsi.

Masa kehidupan reproduksi wanita pada dasarnya dapat di bagi dalam tiga periode yaitu reproduksi muda (15-19 tahun), reproduksi sehat (20-35 tahun),dan reproduksi tua (36-45 tahun). Pembagian ini didasarkan atas dasar data epidemologi yang menyatakan bahwa risiko kehamilan dan persalinan baik bagi ibu maupun bagi anak lebih tinggi pada usia kurang dari 20 tahun, paling rendah pada usia 20-35 tahun, dan meningkat setelah usia lebih dari 35 tahun. Umur yang tidak beresiko dalam kehamilan adalah dari umur 20 tahun sampai dengan 30 tahun, dan yang beresiko dalam kehamilan adalah usia $>35$ tahun. Jenis kontrasepsi yang digunakan sebaiknya disesuaikan dengan tahap masa reproduksi tersebut (Manuaba, 2012).

\section{KESIMPULAN}

\section{DAFTAR RUJUKAN}

Arikunto,Suharsimi.2002. Prosedur Penelitian Suatu Pendekatan Praktek Edisi v. Penerbit Rineka Cipta. Jakarta

BKKBN, 2009. Keluarga Berencana Dan Kesehatan Reproduksi, Kebijakan Program Dan Kegiatan Tahun 2005-2009. Jakarta : BKKBN

Dinas Kesehatan Kota Lubuklinggau, 2013 Data Jumlah Peserta KB. Tahun 2013

Etty (2010) Http://Hasil Penelitian Hubungan Karakteristik Ibu Grande Multipara Dengan Metode Kontrasepsi. Diaakses 24 Juni 2014.

Hartanto, 2009. Keluarga Berencana dan Kontrasepsi. Jakarta : Pustaka Sinar Harapan

Hidayat, Alimul. 2002. Riset Keperawatan. Salemba Medika, Jakarta.

http://ww.tempo.co.id/medika/arsip/032002/PUS-1.html. Diakses 20 januari 2014.

Kusniah (2004) Http://Hasil Penelitian hubungan tingkat Pengetahuan Dengan Keikutsertaan Suami Pada Kb Metode Suntik/. Diaakses 24 Juni 2014.
Berdasarkan dari hasil penelitian mengenai Hubungan Pengetahuan, Jumlah Anak (Paritas) dan Umur Dengan Penggunaan Kontrasepsi Suntik Di Puskesmas Megang Kecamatan Lubuklinggau Utara II Kota Lubuklinggau Tahun 2014. Didapatkan tidak ada hubungan yang bermakna antara Pengetahuan Dengan Penggunaan Kontrasepsi Suntik. Tidak ada hubungan yang bermakna antara Jumlah Anak Dengan Penggunaan Kontrasepsi Suntik. Ada hubungan yang bermakna antara Umur Dengan Penggunaan Kontrasepsi Suntik Di Puskesmas Megang Kecamatan Lubuklinggau Utara II Kota Lubuklinggau Tahun 2014.

Hasil penelitian ini diharapkan menjadi pendorong bagi petugas kesehatan khususnya Puskesmas Megang Kecamatan Lubuklinggau Utara II Kota Lubuklinggau untuk memberikan penyuluhan tentang kelebihan dan kekurangan alat-alat kontrasepsi khususnya kontrasepsi suntik.

Mantra, 2006. Buku Ajar Asuhan Kebidanan edisi 4. Jakarta :EGC.

Manuaba, 2009. Memahami Kesehatan Reproduksi Wanita edisi 2. Jakarta: EGC

Manuaba, 2010 Ilmu Kebidanan, Penyakit Kandungan, dan KB edisi 2. Jakarta: EGC

Maryani, 2008. Cara tepat Memilih Alat Kontrasepsi Keluarga Berencana Bagi Wanita.

Notoatmodjo, S, 2003. Ilmu Kesehatan Masyarakat Prinsip-Prinsip Dasar, Cetakan II, Jakarta.

PKBI, 2010. http://pkbi.or.id/berita/program-keluargaberencana-kb/. Diakses 13 januari 2014.

Sarwono, 2006. Buku Panduan Praktis Pelayanan Kontrasepsi.Jakarta: Yayasan Bina Pustaka

Siregar (2010) Http://Hasil Penelitian Analisis penggunaan alat kontrasepsi suntik pada Akseptor KB di Kelurahan Harjosari, Kecamatan Medan Amplas tahun 2010 Diaakses 24 Juni 2014. 